\title{
Impaired recognition of disgust in amyotrophic lateral sclerosis is related to basal ganglia involvement
}

\author{
Veronica Castelnovo $^{\text {a,e }}$, Elisa Canu ${ }^{a}$, Maria Antonietta Magno ${ }^{\text {a }}$, Silvia Basaia ${ }^{\text {a }}$, Nilo Riva ${ }^{\text {b,d }}$, \\ Barbara Poletti $^{\mathrm{f}}$, Vincenzo Silani ${ }^{\mathrm{f}, g}$, Massimo Filippi ${ }^{\text {a,b,c, d,e }}$, Federica Agosta ${ }^{\text {a,b, e, }}$, \\ ${ }^{a}$ Neuroimaging Research Unit, Division of Neuroscience, IRCCS San Raffaele Scientific Institute, Milan, Italy \\ ${ }^{\mathrm{b}}$ Neurology Unit, IRCCS San Raffaele Scientific Institute, Milan, Italy \\ ${ }^{\mathrm{c}}$ Neurophysiology Service, IRCCS San Raffaele Scientific Institute, Milan, Italy \\ ${ }^{\mathrm{d}}$ Neurorehabilitation Unit, IRCCS San Raffaele Scientific Institute, Milan, Italy \\ e Vita-Salute San Raffaele University, Milan, Italy \\ ${ }^{\mathrm{f}}$ Department of Neurology and Laboratory of Neuroscience, IRCCS Istituto Auxologico Italiano, Milan, Italy \\ ${ }^{g}$ Department of Pathophysiology and Transplantation, "Dino Ferrari" Center, Università degli Studi di Milano, Milan, Italy
}

\section{A R T I C L E I N F O}

\section{Keywords:}

Amyotrophic lateral sclerosis

Basal ganglia

Disgust

Emotions

MRI

\begin{abstract}
A B S T R A T
In the present study we investigated emotion recognition in pure motor amyotrophic lateral sclerosis (ALS) patients and its relationship with the integrity of basal ganglia, hippocampus and amygdala. Twenty ALS patients without either cognitive or behavioural impairment, and 52 matched healthy controls performed a neuropsychological assessment including the Comprehensive Affect Testing System (CATS) investigating emotion recognition. All participants underwent also a 3T brain MRI. Volumes of basal ganglia, hippocampus and amygdala bilaterally were measured using FIRST in FSL. Sociodemographic, cognitive and MRI data were compared between groups. In ALS patients, correlations between CATS significant findings, brain volumes, cognition, mood and behaviour were explored. ALS patients showed altered performances at the CATS total score and, among the investigated emotions, patients were significantly less able to recognize disgust compared with controls. No brain volumetric differences were observed between groups. In ALS patients, a lower performance in disgust recognition was related with a reduced volume of the left pallidum and a lower performance on the Edinburgh Cognitive and Behavioural ALS Screen. Cognitively/behaviourally unimpaired ALS patients showed impaired disgust recognition, which was associated with pallidum volume. The association with cognitive alterations may suggest impaired disgust recognition as an early marker of cognitive decline.
\end{abstract}

\section{Introduction}

Alterations of socioemotional behaviour are important early features of frontotemporal lobar degeneration (FTLD), particularly of the behavioural variant of frontotemporal dementia (FTD) and the semantic variant of primary progressive aphasia (Werner et al., 2007). Social cognition deficits have been reported also in amyotrophic lateral sclerosis (ALS) patients as alterations in theory of mind and emotion processing (Girardi et al., 2011). The first studies on emotion processing in ALS are dated back to 2005 (Lule et al., 2005; Papps et al., 2005), and up to date several investigations reported emotion perception impairment in ALS (Aho-Özhan et al., 2016; Andrews et al., 2017; Crespi et al., 2014;
Crespi et al., 2016; Girardi et al., 2011; Lule et al., 2005; Oh et al., 2016; Palmieri et al., 2010; Zimmerman et al., 2007), such as emotion recognition (both facial and prosodic), emotion attribution, and reduced psychophysiological excitability to emotional stimuli (Benbrika et al., 2019). According to a recent meta-analysis, the most frequent alteration in ALS patients is in facial recognition for disgust and surprise (Bora, 2017), followed by inability in recognizing anger (Andrews et al., 2017; Crespi et al., 2014; Girardi et al., 2011; Oh et al., 2016; Savage et al., 2014; Zimmerman et al., 2007) and sadness (Aho-Özhan et al., 2016; Andrews et al., 2017; Oh et al., 2016; Zimmerman et al., 2007). On the other hand, recognition of fear and happiness seems to be relatively spared (Aho-Özhan et al., 2016; Girardi et al., 2011). Although emotion

\footnotetext{
* Corresponding author at: Neuroimaging Research Unit, Division of Neuroscience, and Neurology Unit, IRCCS San Raffaele Scientific Institute, Vita-Salute San Raffaele University, Via Olgettina, 60, 20132 Milan, Italy.

E-mail address: agosta.federica@hsr.it (F. Agosta).
} 
processing deficits in ALS have been observed both in patients with and without cognitive impairment (Andrews et al., 2017; Crespi et al., 2014; Crespi et al., 2016; Girardi et al., 2011), whether they appear before and/or regardless of cognitive and behavioural abnormalities is still not clear.

Previous MRI studies on emotion processing in ALS reported associations with the neurodegeneration of cortical and limbic brain structures. Specifically, in ALS patients an increased emotion attribution ability was related to greater gray matter (GM) density of the right fronto-insular and anterior cingulate cortices (Cerami et al., 2014). Furthermore, two diffusion tensor imaging studies (Crespi et al., 2014; Crespi et al., 2016) observed a relationship between emotion recognition difficulties in ALS patients and microstructural changes in ventral associative bundles connecting occipital, temporo-limbic and orbitofrontal regions of the right hemisphere. Finally, task-based functional MRI (fMRI) studies including paradigms which present emotional words, Ekman's faces or pictures of people in social situations (AhoÖzhan et al., 2016; Lule et al., 2007; Palmieri et al., 2010) reported higher activation in the bilateral inferior frontal gyrus and right supramarginal area, and reduced activation in the bilateral hippocampus and extrastriate visual areas in ALS patients compared with healthy controls.

In ALS, basal ganglia damage appears in the stages 3 and 4 of TDP-43 pathology (Brettschneider et al., 2013) and was confirmed by several MRI studies (Bede et al., 2013a; Bede et al., 2013b; Verstraete et al., 2014; Westeneng et al., 2015). Structural and task-based functional MRI investigations (Abidi et al., 2020; Feron et al., 2018) highlighted a role of basal ganglia in mediating extra-pyramidal motor manifestations and gait impairment in ALS. Recent works found correlations between cognitive deficits, apathy and basal ganglia damage (Machts et al., 2015) or frontostriatal circuits (Castelnovo et al., 2020) in ALS patients (Castelnovo et al., 2020; Machts et al., 2015). Regional shape contractions of the bilateral pallidum, right putamen, and right accumbens were recently observed in cognitively/behaviourally unimpaired ALS patients compared to controls, suggesting that basal ganglia are involved early in the disease course (Tae et al., 2020). Due to the growing attention on basal ganglia, we decided to focus the present work on these brain regions.

In a sample of early diagnosed ALS patients without cognitive and behavioural deficits, the aim of our study was twofold: 1) to identify which emotions are altered in ALS compared to healthy controls; and 2) to investigate the relationship between emotion recognition and the integrity of basal ganglia, hippocampus and amygdala. For these purposes, we used a specific battery, the Comprehensive Affect Testing System (CATS), which investigates several subcomponents of the emotion processing.

\section{Materials and methods}

\subsection{Participants}

From a sample of 72 MND cases prospectively recruited at IRCCS San Raffaele Scientific Institute in Milan, Italy, from 2017 to 2019, we selected 20 sporadic ALS patients (Brooks et al., 2000) with no significant respiratory failure. We included only patients with available clinical assessment, neuropsychological assessment including an evaluation of emotion processing (see details below) and brain 3T MRI scan, with no cognitive and/or behavioural impairment according to Strong's criteria (Strong et al., 2017), and no mood alterations. All patients were screened for known pathogenic mutations, including C9orf72. Fifty-two healthy controls, age-, sex-, and education-matched with patients were recruited among non-consanguineous relatives and by word of mouth based on the following criteria: normal neurological exam, mini mental state examination (MMSE) score $\geq 28$, and no family history for neurodegenerative diseases. Healthy controls underwent neuropsychological assessment and brain MRI scan. All participants were excluded if they had significant medical illnesses or substance abuse that could interfere with cognitive functioning; any (other) major systemic, psychiatric, or neurological illnesses; and (other) causes of focal or diffuse brain damage, including cerebrovascular disease at conventional MRI scans. No participants were excluded for motion-related artifacts in the MR images.

\subsubsection{Standard protocol approvals, registrations, and patient consents}

Local ethical standards committee on human experimentation approved the study protocol and all participants provided written informed consent (Ethical committee numbers: GR-2013-02357415 and StG-2016_714388_NeuroTRACK).

\subsection{Clinical assessment}

Disease severity in patients was assessed using the ALS Functional Rating Scale-revised (ALSFRS-R, with a maximum score of 48) (Cedarbaum et al., 1999). The rate of disease progression was defined according to the following formula: (48-ALSFRS-R score)/time between symptom onset and first visit.

\subsection{Genetic analysis}

Blood samples were collected from all patients and healthy controls. The presence of GGGGCC hexanucleotide expansion in the first intron of C9orf72 was assessed using a repeat-primed polymerase chain reaction (PCR) assay (Renton et al., 2011). A cut-off of $\geq 30$ repeats combined with a typical saw-tooth pattern was considered pathological. In addition, the coding sequences and intron/exon boundaries of GRN, MAPT, TARDBP, SOD1, FUS, TBK1, TREM2, OPTN and VCP genes were amplified by PCR using optimized protocols, looking for known pathogenic mutations (Pozzi et al., 2017).

\subsection{Cognitive and behavioural assessment}

Neuropsychological assessments were performed by experienced neuropsychologists, unaware of the MRI results. Cognitive evaluation consisted in the administration of a comprehensive neuropsychological battery in order to define performance differences in patients and controls, and the potential presence of cognitive and/or behavioural impairment according to Strong's criteria in ALS patients (Strong et al., 2017).

In the neuropsychological battery, the following cognitive functions were administered to patients as previously described (Castelnovo et al., 2021): global cognitive functioning with the MMSE and the Edinburgh Cognitive and Behavioural ALS Screen (ECAS); long and short term verbal memory with the Rey Auditory Verbal Learning Test and the digit span forward, respectively; executive functions with the digit span backward, the Cognitive Estimation Task (CET), the Modified Card Sorting Test; fluency with the phonemic and semantic fluency tests and the relative fluency indices (controlling for individual motor disabilities); language with the confrontation naming subtests of Italian battery for the assessment of aphasic disorders (BADA); emotion processing with the CATS; mood with the Hamilton Depression Rating Scale (HDRS); and the presence of behavioural disturbances with the Amyotrophic Lateral Sclerosis-Frontotemporal Dementia-Questionnaire (ALS-FTD-Q) administered to patients' caregivers. Healthy controls underwent the entire assessment except for the ECAS, CET and BADA subtests; moreover, in healthy controls the Beck Depression Inventory (BDI) was used to assess mood.

The CATS is a battery which investigates different aspects of the emotion processing by using the Ekman's faces expressing the six basic emotions (disgust, surprise, happiness, anger, fear and sadness) (Froming et al., 2006). From this battery, we selected and administered six subtests: identity discrimination (which is the control condition that investigates the correct discrimination of faces with no emotion involvement), affect discrimination, affect naming, affect matching, 
affect selection, affect confrontation (Fig. 1).

Based on the number of correct answers, we obtained a total score and specific scores for each CATS subdomain. Finally, composite scores were calculated by summing up the correct answers for each of the six basic emotions.

\subsection{MRI acquisition}

Using a 3.0 T scanner (Ingenia CX, Philips), the following brain MRI sequences were obtained from all participants: 3D T1-weighted (TFE) $(\mathrm{TR}=7 \mathrm{~ms} ; \mathrm{TE}=3.2 \mathrm{~ms}$; flip angle $=9$ [degrees]; 204 contiguous sagittal slices with voxel size $=1 \times 1 \times 1 \mathrm{~mm}$, matrix size $=256 \times 240$, FOV $=256 \times 240 \mathrm{~mm}^{2}$ ); 3D FLAIR (TR $=4800 \mathrm{~ms}$; TE $=267 \mathrm{~ms}$; $\mathrm{TI}=$ $1650 \mathrm{~ms} ; \mathrm{ETL}=167 ; \mathrm{NEX}=2 ; 192$ contiguous sagittal slices with voxel size $=0.89 \times 0.89 \times 1 \mathrm{~mm}$, matrix size $=256 \times 256$, FOV $=256 \times 256$ $\left.\mathrm{mm}^{2}\right)$; 3D T2 $(\mathrm{TR}=2500 \mathrm{~ms} ; \mathrm{TE}=330 \mathrm{~ms} ; \mathrm{ETL}=117 ; \mathrm{NEX}=1 ; 192$ contiguous sagittal slices with voxel size $=0.89 \times 0.89 \times 1 \mathrm{~mm}$, matrix size $=256 \times 258$, FOV $=256 \times 256 \mathrm{~mm}^{2}$ ).

\subsection{MRI analysis}

MRI analysis was performed at the Neuroimaging Research Unit, IRCCS Scientific Institute San Raffaele, Milan, Italy. The potential presence of white matter hyperintensities was evaluated on 3D FLAIR and 3D T2-weighted images. FMRIB's Integrated Registration and Segmentation Tool (FIRST) in FSL (http://www.fmrib.ox.ac.uk/fsl/first/i ndex.html) was applied to TFE images of each subject and used to automatically segment GM regions, i.e., caudate, pallidum, putamen, thalamus and nucleus accumbens, amygdala and hippocampus, bilaterally. Mean GM volumes were calculated and multiplied by the normalization factor derived from SIENAx to correct for subject head size (http://www. fmrib.ox.ac.uk/fsl/sienax/index.html).

\subsection{Statistical analysis}

To compare the sociodemographic characteristics, cognitive performances and MRI data between groups, we used Kruskal-Wallis one-way ANOVA models followed by post-hoc pairwise comparisons (using $U$ test of Mann-Whitney and Bonferroni-correction for multiple comparisons) and Fisher's exact test for continuous and categorical variables, respectively.

In ALS patients and controls, CATS significant findings were correlated with the volumes of basal ganglia, hippocampus and amygdala, patients' performances at the ECAS, patients' mood (HDRS) and behaviour (ECAS behaviour score and ALS-FTD-Q) using Pearson's correlation analysis. The statistical analyses were performed with using
SPSS software (version 24.0; IBM Corp., Armonk, NY, USA). All analyses were performed with using the same models also excluding those patients with C9orf72 mutation.

\section{Results}

ALS patients and healthy controls were similar in age, sex and education (Table 1). Two patients were C9orf72 mutation carriers. According to Strong's criteria (Strong et al., 2017), none of the patients were classified as cognitively and/or behaviourally impaired. No patients nor controls showed depression according to self-administered questionnaires (HDRS or BDI) and/or clinical interview. At the time of the visit, $25 \%$ of patients were on stable SSRI-type antidepressants and $5 \%$ on benzodiazepines. The neuropsychological assessment reveals that patients performed similarly to controls in all considered cognitive domains (Table 1).

At the CATS, patients performed worse than controls in the total score, affect selection and affect matching subtests (Table 2). When the emotion target was disgust, patients provided less correct answers than controls (Table 2).

These latter differences remained significant when the analyses were re-run without the two C9orf72 patients ( $\mathrm{p}=0.04)$. For the other target emotions, the two groups showed similar scores.

ALS patients and controls did not differ in any of the investigated GM volumes (Table 3 ).

In ALS patients, a positive relationship was observed between the disgust correct recognition at the CATS (number of correct answers when disgust was the emotion target) and the volume of the left pallidum (Fig. 2). When this analysis was re-run without the two C9orf72 patients, a trend toward statistical significance was observed $(r=0.459$; $\mathrm{p}=0.056$ ). Furthermore, in ALS patients, a positive relationship was found between disgust correct recognition at the CATS and patients' performance at the ECAS ALS-specific and executive functions scores (ECAS was administered to 17 patients; Fig. 2).

When these analysis were re-run without the two C9orf72 patients, a significant correlation was still observed $(\mathrm{r}=0.625 ; \mathrm{p}=0.013$ and $\mathrm{r}=$ $0.659 ; \mathrm{p}=0.01$, respectively). In patients, no relationships were observed between CATS disgust correct recognition and degree of depression and behavioural disturbances assessed with the ECAS and ALS-FTD-Q (ALS-FTD-Q was administered to 18 patients). In controls, no relationship was observed between disgust correct recognition at the CATS and the volumes of the pallidum.

\section{Discussion}

In a sample of cognitively and behaviourally unimpaired patients

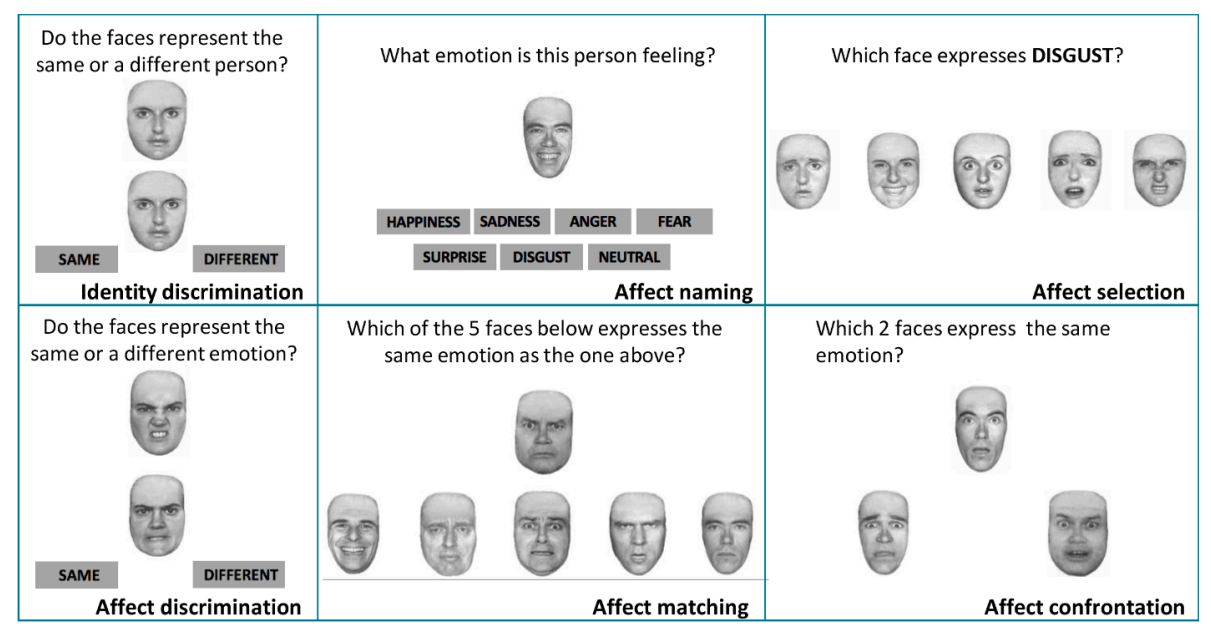

Fig. 1. The six subtests of the Comprehensive Affect Testing System (CATS). For illustrative purposes, the stimuli represent an adaptation of the original version. 
Table 1

Sociodemographic, clinical and cognitive features of the sample.

\begin{tabular}{|c|c|c|c|c|c|}
\hline & $\begin{array}{l}\text { Healthy } \\
\text { controls }\end{array}$ & $\begin{array}{l}\text { ALS } \\
\text { patients }\end{array}$ & $\begin{array}{l}\text { F } \\
\text { value }\end{array}$ & $\begin{array}{l}\text { Effect } \\
\text { size }\end{array}$ & $\begin{array}{l}P \\
\text { value }\end{array}$ \\
\hline $\mathbf{N}$ & 52 & 20 & - & - & - \\
\hline Sex [women] & $33(63 \%)$ & $11(55 \%)$ & 0.435 & 0.006 & 0.35 \\
\hline Age at MRI [years] & $\begin{array}{l}60.36 \pm \\
8.49\end{array}$ & $\begin{array}{l}57.98 \pm \\
11.35\end{array}$ & 0.819 & 0.012 & 0.37 \\
\hline Education [years] & $\begin{array}{l}12.40 \pm \\
3.79\end{array}$ & $\begin{array}{l}12.55 \pm \\
4.99\end{array}$ & 0.124 & 0.002 & 0.73 \\
\hline $\begin{array}{l}\text { Handedness } \\
\text { [right] }\end{array}$ & $50(96 \%)$ & $20(100 \%)$ & & & \\
\hline $\begin{array}{l}\text { Disease duration } \\
\text { [months] }\end{array}$ & - & $\begin{array}{l}25.64 \pm \\
18.18\end{array}$ & - & - & - \\
\hline ALSFRS-R, 0-48 & - & $\begin{array}{l}39.00 \pm \\
7.53\end{array}$ & - & - & - \\
\hline $\begin{array}{l}\text { Disease } \\
\text { progression rate }\end{array}$ & - & $\begin{array}{l}0.53 \pm \\
0.47\end{array}$ & - & - & - \\
\hline $\begin{array}{l}\text { Site of onset, limb } \\
\text { Global cognition }\end{array}$ & - & $86 \%$ & - & - & - \\
\hline MMSE & $\begin{array}{l}29.36 \pm \\
0.80\end{array}$ & $\begin{array}{l}28.63 \pm \\
1.80\end{array}$ & 1.946 & 0.29 & 0.16 \\
\hline ECAS, * Language & - & $\begin{array}{l}24.65 \pm \\
3.94\end{array}$ & - & - & - \\
\hline ECAS, * Fluency & - & $\begin{array}{l}19.65 \pm \\
2.76\end{array}$ & - & - & - \\
\hline $\begin{array}{l}\text { ECAS, * Executive } \\
\text { functions }\end{array}$ & - & $\begin{array}{l}38.65 \pm \\
3.46\end{array}$ & - & - & - \\
\hline $\begin{array}{l}\text { ECAS,* ALS-specific } \\
\text { functions }\end{array}$ & - & $\begin{array}{l}82.65 \pm \\
8.29\end{array}$ & - & - & - \\
\hline ECAS, * Memory & - & $\begin{array}{l}18.47 \pm \\
2.92\end{array}$ & - & - & - \\
\hline ECAS,* Visuospatial & - & $\begin{array}{l}11.53 \pm \\
0.62\end{array}$ & - & - & - \\
\hline $\begin{array}{l}\text { ECAS,* ALS non- } \\
\text { specific functions }\end{array}$ & - & $\begin{array}{l}30.00 \pm \\
3.04\end{array}$ & - & - & - \\
\hline ECAS, * total score & - & $\begin{array}{l}111.82 \pm \\
10.06\end{array}$ & - & - & - \\
\hline \multicolumn{6}{|l|}{ Memory } \\
\hline Digit span, forward & $5.96 \pm 1.07$ & $\begin{array}{l}5.56 \pm \\
1.34\end{array}$ & 1.886 & 0.028 & 0.17 \\
\hline $\begin{array}{l}\text { Digit span, } \\
\text { backward }\end{array}$ & $4.82 \pm 1.20$ & $\begin{array}{l}4.56 \pm \\
0.98\end{array}$ & 0.461 & 0.007 & 0.50 \\
\hline RAVLT, immediate & $\begin{array}{l}49.62 \pm \\
7.08\end{array}$ & $\begin{array}{l}45.95 \pm \\
9.02\end{array}$ & 2.521 & 0.037 & 0.11 \\
\hline RAVLT, delayed & $\begin{array}{l}10.92 \pm \\
2.42\end{array}$ & $\begin{array}{l}9.95 \pm \\
2.06\end{array}$ & 2.945 & 0.043 & 0.09 \\
\hline \multicolumn{6}{|l|}{ Executive function } \\
\hline CET & - & $\begin{array}{l}13.36 \pm \\
3.48\end{array}$ & - & - & - \\
\hline $\begin{array}{l}\text { MCST, perseverative } \\
\text { responses }\end{array}$ & $3.52 \pm 3.63$ & $\begin{array}{l}4.71 \pm \\
6.49\end{array}$ & 0.133 & 0.002 & 0.72 \\
\hline \multicolumn{6}{|l|}{ Language } \\
\hline BADA (nouns) & - & $\begin{array}{l}28.86 \pm \\
1.22\end{array}$ & - & - & - \\
\hline BADA (actions) & - & $\begin{array}{l}27.71 \pm \\
1.50\end{array}$ & - & - & - \\
\hline \multicolumn{6}{|l|}{ Fluency } \\
\hline $\begin{array}{l}\text { Phonemic fluency, } \\
\text { Index }\end{array}$ & $5.10 \pm 1.84$ & $\begin{array}{l}4.22 \pm \\
1.56\end{array}$ & 3.474 & 0.062 & 0.06 \\
\hline $\begin{array}{l}\text { Semantic fluency, } \\
\text { Index }\end{array}$ & $3.81 \pm 1.58$ & $\begin{array}{l}4.12 \pm \\
1.48\end{array}$ & 0.434 & 0.008 & 0.51 \\
\hline \multicolumn{6}{|l|}{ Mood \& Behaviour } \\
\hline BDI & $7.04 \pm 4.81$ & - & - & - & - \\
\hline HDRS & - & $\begin{array}{l}4.68 \pm \\
2.69\end{array}$ & - & - & - \\
\hline $\begin{array}{l}\text { ECAS, * behaviour } \\
\text { score }\end{array}$ & - & $\begin{array}{l}0.19 \pm \\
0.40\end{array}$ & - & - & - \\
\hline ALS-FTD-Q & - & $\begin{array}{l}8.10 \pm \\
13.11\end{array}$ & - & - & - \\
\hline
\end{tabular}

Values denote mean \pm standard deviations or numbers (frequency). $\mathrm{P}$ values refer to Kruskal-Wallis one-way ANOVA models followed by post-hoc pairwise comparisons (using $U$ test of Mann-Whitney and Bonferroni-correction for multiple comparisons) and Fisher's exact test for continuous and categorical variables, respectively. *ALS-FTD-Q was administered to 18 patients. *ECAS was administered to 17 patients. Abbreviations: ALS = Amyotrophic Lateral Sclerosis; ALSFRS-R = ALS Functional Rating Scale Revised; ALS-FTD-Q =
Amyotrophic Lateral Sclerosis-Frontotemporal Dementia-Questionnaire; BADA $=$ Italian battery for the assessment of aphasic disorders; BDI = Beck Depression Inventory; CET = Cognitive Estimation Task; ECAS = Edinburgh cognitive and behavioural ALS screen; HDRS = Hamilton depression rating scale; MCST = Modified Card Sorting Test; MMSE = Mini Mental State Examination; MRI = Magnetic Resonance Imaging; RAVLT = Rey Auditory Verbal Learning Test.

Table 2

Performances of healthy controls and ALS patients at the Comprehensive Affect Testing System.

\begin{tabular}{|c|c|c|c|c|c|}
\hline & $\begin{array}{l}\text { Healthy } \\
\text { controls }\end{array}$ & $\begin{array}{l}\text { ALS } \\
\text { patients }\end{array}$ & $\begin{array}{l}\text { F } \\
\text { value }\end{array}$ & $\begin{array}{l}\text { Effect } \\
\text { size }\end{array}$ & $\begin{array}{l}P \\
\text { value }\end{array}$ \\
\hline CATS Total score & $\begin{array}{l}56.79 \pm \\
4.77\end{array}$ & $\begin{array}{l}53.05 \pm \\
5.08\end{array}$ & 8.766 & 0.123 & 0.003 \\
\hline $\begin{array}{l}\text { CATS Identity } \\
\text { Discrimination }\end{array}$ & $\begin{array}{l}11.81 \pm \\
0.40\end{array}$ & $\begin{array}{l}11.45 \pm \\
1.05\end{array}$ & 1.522 & 0.021 & 0.22 \\
\hline $\begin{array}{l}\text { CATS Affect } \\
\text { Discrimination }\end{array}$ & $\begin{array}{l}11.59 \pm \\
0.98\end{array}$ & $\begin{array}{l}10.95 \pm \\
0.95\end{array}$ & 2.654 & 0.037 & 0.10 \\
\hline CATS Affect Naming & $4.63 \pm 0.97$ & $\begin{array}{l}4.50 \pm \\
1.15\end{array}$ & 0.247 & 0.003 & 0.62 \\
\hline $\begin{array}{c}\text { CATS Affect } \\
\text { Selection }\end{array}$ & $5.52 \pm 0.67$ & $\begin{array}{l}5.05 \pm \\
0.95\end{array}$ & 4.166 & 0.059 & 0.04 \\
\hline $\begin{array}{c}\text { CATS Affect } \\
\text { Matching }\end{array}$ & $9.31 \pm 1.92$ & $\begin{array}{l}8.05 \pm \\
1.40\end{array}$ & 7.950 & 0.112 & 0.005 \\
\hline $\begin{array}{l}\text { CATS Affect } \\
\text { Confrontation }\end{array}$ & $\begin{array}{l}14.23 \pm \\
3.04\end{array}$ & $\begin{array}{l}13.05 \pm \\
3.35\end{array}$ & 2.617 & 0.037 & 0.11 \\
\hline $\begin{array}{l}\text { Disgust, correct } \\
\text { answers (0-9) }\end{array}$ & $5.85 \pm 1.50$ & $\begin{array}{l}4.75 \pm \\
1.83\end{array}$ & 6.060 & 0.085 & 0.01 \\
\hline $\begin{array}{l}\text { Surprise, correct } \\
\text { answers }(0-8)\end{array}$ & $6.56 \pm 1.34$ & $\begin{array}{l}6.35 \pm \\
0.93\end{array}$ & 1.458 & 0.021 & 0.23 \\
\hline $\begin{array}{l}\text { Happiness, correct } \\
\text { answers }(0-9)\end{array}$ & $8.65 \pm 0.52$ & $\begin{array}{l}8.45 \pm \\
0.69\end{array}$ & 1.309 & 0.018 & 0.25 \\
\hline $\begin{array}{l}\text { Anger, correct } \\
\text { answers }(0-10)\end{array}$ & $5.69 \pm 2.11$ & $\begin{array}{l}4.80 \pm \\
1.61\end{array}$ & 3.053 & 0.043 & 0.08 \\
\hline $\begin{array}{l}\text { Fear, correct } \\
\text { answers (0-8) }\end{array}$ & $5.15 \pm 1.29$ & $\begin{array}{l}5.45 \pm \\
1.28\end{array}$ & 0.564 & 0.008 & 0.45 \\
\hline $\begin{array}{l}\text { Sadness, correct } \\
\text { answers (0-9) }\end{array}$ & $6.90 \pm 1.54$ & $\begin{array}{l}6.10 \pm \\
1.89\end{array}$ & 2.622 & 0.037 & 0.11 \\
\hline
\end{tabular}

Values denote mean \pm standard deviations. P values refer to Kruskal-Wallis oneway ANOVA models followed by post-hoc pairwise comparisons (using $U$ test of Mann-Whitney and Bonferroni-correction for multiple comparisons). BOLD p values denote significant differences between groups at $\mathrm{p}<0.05$. Abbreviations: ALS $=$ Amyotrophic Lateral Sclerosis; CATS = Comprehensive Affect Testing System.

with ALS, we observed an altered ability to correctly recognize disgust and a potential role of the basal ganglia, specifically of the left pallidum, in the altered processing of this emotion.

The finding of disgust recognition difficulties in ALS patients is in line with previous studies, which investigated the emotional processing in these patients, mainly during the processing of facial expressions from the Ekman's series (Aho-Özhan et al., 2016; Andrews et al., 2017; Crespi et al., 2014; Girardi et al., 2011; Oh et al., 2016; Zimmerman et al., 2007). What should be underlined about the impairment in recognising emotions, and specifically disgust in ALS, are the clinical implications on everyday life for patients and caregivers. Disgust is an adaptative emotion, which together with fear, has implications for human survival since the origin of our species (Castillo-Huitron et al., 2020). It is considered as a "moral" emotion, since it helps us to react toward something representing a risk-like situation, act and people, by producing strong internal signals of avoidance (Eckart et al., 2012; Rozin et al., 2009). Given that everyday life often requires us to identify the emotions of several faces, these difficulties, even if subtle, could have a negative impact on social interactions, and also important moral implications. Awareness of difficulties in emotion processing becomes crucial in life-limiting and physically debilitating diseases as ALS, where keeping social relationships is fundamental to safeguard good quality of life (Swinnen and Robberecht, 2014). Since emotional and social deficits may lead to poorer quality of life and increased carer burden (Caga et al., 2019), the study of social cognition in ALS has been focus of increasing 
Table 3

Gray matter volumes in healthy controls and ALS patients.

\begin{tabular}{|c|c|c|c|c|c|}
\hline & Healthy controls & ALS patients & F value & Effect size & $P$ value \\
\hline L caudate & $4427.33 \pm 388.76$ & $4534.65 \pm 500.52$ & 0.710 & 0.010 & 0.40 \\
\hline L pallidum & $2391.91 \pm 253.82$ & $2450.66 \pm 280.97$ & 0.913 & 0.013 & 0.34 \\
\hline L putamen & $6489.57 \pm 595.81$ & $6410.40 \pm 556.56$ & 0.031 & 0.000 & 0.86 \\
\hline L accumbens & $694.62 \pm 129.06$ & $649.88 \pm 126.93$ & 1.089 & 0.015 & 0.30 \\
\hline L thalamus & $10509.67 \pm 819.14$ & $10168.84 \pm 523.05$ & 2.201 & 0.031 & 0.14 \\
\hline L hippocampus & $5228.55 \pm 665.85$ & $5069.76 \pm 378.92$ & 2.164 & 0.030 & 0.14 \\
\hline L amygdala & $1793.19 \pm 243.30$ & $1731.25 \pm 223.50$ & 1.089 & 0.000 & 0.30 \\
\hline$R$ caudate & $4690.06 \pm 421.20$ & $4792.63 \pm 542.87$ & 0.266 & 0.004 & 0.61 \\
\hline $\mathrm{R}$ pallidum & $2420.09 \pm 274.77$ & $2444.17 \pm 291.22$ & 0.162 & 0.002 & 0.69 \\
\hline $\mathrm{R}$ putamen & $6262.95 \pm 562.95$ & $6290.94 \pm 526.22$ & 0.003 & 0.000 & 0.96 \\
\hline $\mathrm{R}$ accumbens & $530.60 \pm 129.39$ & $498.75 \pm 121.47$ & 0.710 & 0.010 & 0.40 \\
\hline $\mathrm{R}$ thalamus & $10206.60 \pm 835.17$ & $9767.73 \pm 543.74$ & 3.416 & 0.048 & 0.07 \\
\hline $\mathrm{R}$ hippocampus & $5309.90 \pm 691.76$ & $5094.08 \pm 368.83$ & 3.098 & 0.044 & 0.08 \\
\hline $\mathrm{R}$ amygdala & $1692.05 \pm 294.43$ & $1707.46 \pm 262.09$ & 0.013 & 0.000 & 0.91 \\
\hline
\end{tabular}

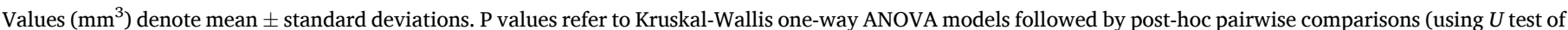
Mann-Whitney and Bonferroni-correction for multiple comparisons). Abbreviations: ALS = Amyotrophic Lateral Sclerosis.
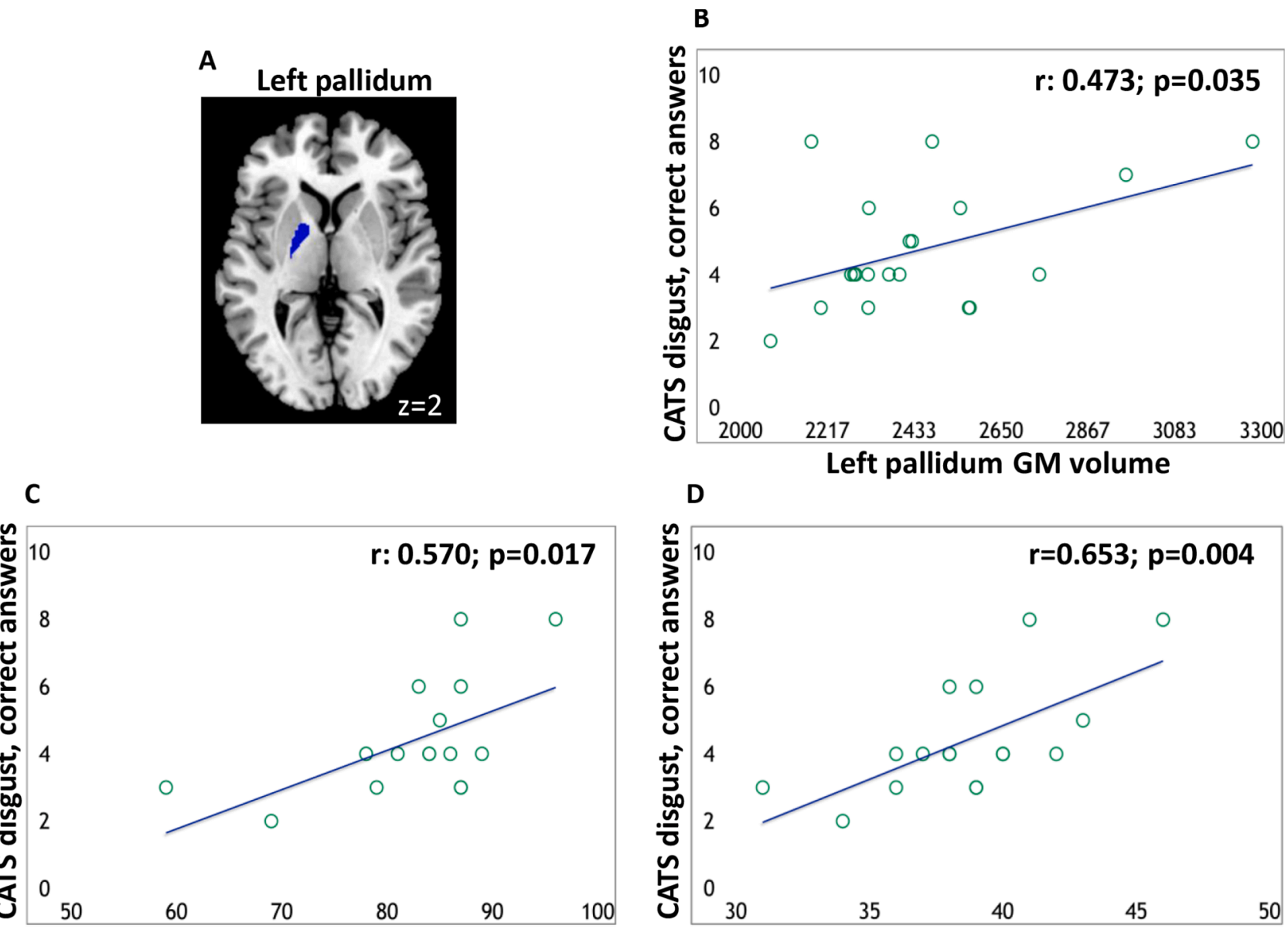

ECAS, ALS-specific score

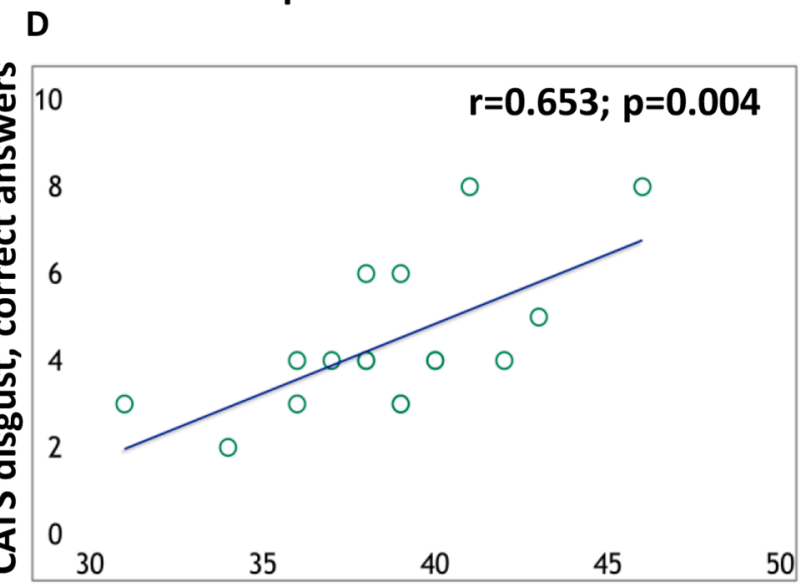

ECAS, executive functions score

Fig. 2. Region of interest (left pallidum) overlaid on the Montreal Neurological Institute template (A); relationship between disgust recognition and volume of the left pallidum (B) and between disgust recognition and ECAS ALS-specific and executive function score (C and D, respectively). R values are Pearson's correlation coefficients. ECAS scores were available for 17 patients only. Abbreviations: CATS = Comprehensive Affect Testing System; GM $=$ grey matter; ECAS $=$ Edinburgh cognitive and behavioural ALS screen.

attention over the past few years. Changes in emotional processing in ALS have been described in an early report by Lulè and colleagues (Lule et al., 2005), who demonstrated that patients judged socio-emotional stimuli as more positive than controls and exhibited reduced subjective arousal. Caregivers of ALS patients meeting also criteria for FTD described a significant reduction of their empathic concern and perspective-taking abilities after disease onset (Arshad et al., 2020).
From the current literature, we know that impairment in empathy, emotion recognition, fluency and executive functions are present also in non-demented ALS, sharing similarities with behavioral changes and cognitive decline in bvFTD (Beeldman et al., 2018). Thus, studies examining management of bvFTD may be relevant to ALS, though caution should be used in extrapolating their conclusions.

Disgust-recognition alterations have been previously reported in a 
sample of bulbar ALS patients in whom the half presented dementia (Zimmerman et al., 2007), in a sample of non-demented sporadic ALS of which only 14/22 were pure motor (Crespi et al., 2014), and in a sample of Korean ALS patients who presented different levels of cognitive dysfunction (Oh et al., 2016). The absence of impairment in cognition, behaviour and in the recognition of other emotions in our sample suggests that disgust could be the first emotion that ALS patients misrecognize in the course of the disease. The relationship we observed between the altered disgust recognition and the performance at the ECAS ALS-specific score and ECAS executive functions score, may suggest impaired disgust recognition as an early marker of cognitive decline. Therefore, from a clinical point of view, it would be important to assess regularly cognition, including social cognition and, in particular, emotional processing, also in those patients without manifest cognitive deficits.

There is an ongoing debate about whether impaired emotion recognition in neurodegenerative disorders, such as ALS, is linked to a more general cognitive decline or if it is independent of other cognitive processes. Specifically, some researchers suggested a causative role of executive dysfunctions in the social cognition impairment in ALS patients (Bora, 2017; Savage et al., 2014; Watermeyer et al., 2015), others reported social cognitive impairment, in absence of frontal lobe dysfunctions (Consonni et al., 2016; Girardi et al., 2011; Lule et al., 2005). On the other hand, a relationship was not observed with the degree of depression or behavioural disturbances. Larger longitudinal studies are needed to confirm the specificity of disgust recognition deficit in ALS and its predictive value.

In our study, we observed an association between disgust recognition ability and the pallidum volume in ALS patients, while such a finding was not present in controls. Thus, this relationship was unique for patients only and could reflect an initial vulnerability of this brain region in cognitively and behavioural unimpaired ALS with starting emotional processing failure. Several studies define the anteroventral insula as a point of convergence for disgust, which has reciprocal connections with several other brain regions including the somatomotor orofacial area and the pallidum, both involved in disgust sensitivity (Calder et al., 2007). According to a meta-analysis of 106 positron emission tomography and fMRI studies on human emotions, the most consistently activated regions for facial expression of disgust are insula/operculum and pallidum (Murphy et al., 2003). More specifically, several studies define the ventral pallidum as an "hedonic hot spot," which supports the sensory experience of disgust, controlling negative motivation to produce avoidance behaviour (Calder et al., 2007; Ho and Berridge, 2014; Holtmann et al., 2020).

Interestingly, disgust misrecognition in our patients was related with the left pallidum volume. One prominent set of functional neuroimaging studies supported a left rather than a right activation of insular cortex to disgust stimuli (Royet et al., 2003; Small et al., 2003; Sprengelmeyer et al., 1998; Wicker et al., 2003). This was also observed in a study where authors applied a direct electrical stimulation of the insula in awake surgery in patients with a left hemisphere tumor, which demonstrated a selective decrease of disgust recognition, compared to other emotional facial expressions (Papagno et al., 2016). Furthermore, a recent study reported that left-lesioned patients in the insular cortexbasal ganglia complex presented significantly lower disgust composite scores compared to right-lesioned patients, or healthy controls, and suggested a primarily left-hemispheric basis of disgust (Holtmann et al., 2020). Authors attributed this lateralized functional difference to a potential psychobiological mechanism. They suggested that, since the left insular cortex supports the modulation of the parasympathetic tone, and since the activation of the parasympathetic nervous system is essential in initiating disgust responses, the lesions to the left insular cortex could alter the integration of information necessary to successfully process disgust (Guo et al., 2016; Holtmann et al., 2020). Finally, an effect of handedness on hemispheric specialization for disgust processing cannot be ruled out. However, this has not been demonstrated yet since all studies on disgust, including the present, involved mainly right-handers.

One of the major limitations of our study is the relatively small sample size, which could have led to negative findings. Second, it is a cross-sectional study, thus the evolving trajectory of emotion recognition deficits in these patients as well as their ability to predict ALS prognosis should be further investigated. Third, no volumetric differences between ALS patients and controls were observed. However, the unique association between pallidum volume and disgust recognition in our group of patients suggests a potential role of this subcortical region in the early alterations of emotional processing in ALS. Finally, we could not identify which emotions (among fear, anger, surprise, happiness and sadness) were more frequently confused with disgust, since the CATS has not been implemented with this purpose.

\section{Conclusions}

In conclusion, this is the first study which demonstrates an altered ability to correctly recognize disgust and a potential role of the left pallidum in the altered processing of this emotion in a sample of cognitively and behaviourally unimpaired ALS patients. Although the specific involvement of disgust (and not of other emotions) in pure motor ALS needs to be confirmed, these findings, together with the relationship between the altered disgust recognition with worse ECAS performance, suggest that disgust could be one of the first emotion that ALS patients fail to recognize in the course of the cognitive decline.

\section{Funding}

This work was supported by the Italian Ministry of Health [GR-201302357415] and the European Research Council [StG2016_714388_NeuroTRACK].

\section{CRediT authorship contribution statement}

Veronica Castelnovo: Conceptualization, Methodology, Resources, Formal analysis, Investigation, Data curation, Writing - original draft, Writing - review \& editing, Visualization. Elisa Canu: Conceptualization, Methodology, Resources, Formal analysis, Investigation, Data curation, Writing - original draft, Writing - review \& editing, Visualization, Project administration, Funding acquisition. Maria Antonietta Magno: Formal analysis, Writing - review \& editing. Silvia Basaia: Formal analysis, Writing - review \& editing. Nilo Riva: Resources, Writing - review \& editing. Barbara Poletti: Conceptualization, Writing - review \& editing. Vincenzo Silani: Writing - review \& editing. Massimo Filippi: Conceptualization, Resources, Writing - review \& editing, Supervision. Federica Agosta: Conceptualization, Supervision, Writing - original draft, Writing - review \& editing, Funding acquisition, Project administration.

\section{Declaration of Competing Interest}

The authors declare the following financial interests/personal relationships which may be considered as potential competing interests: V. Castelnovo, M.A. Magno, S. Basaia, N. Riva, B. Poletti report no disclosures. E. Canu has received research supports from the Italian Ministry of Health. V. Silani received compensation for consulting services and/or speaking activities from AveXis, Cytokinetics and Italfarmaco; and receives or has received research supports form the Italian Ministry of Health, AriSLA (Fondazione Italiana di Ricerca per la SLA), and ERare Joint Transnational Call. M. Filippi is Editor-in-Chief of the Journal of Neurology and Associate Editor of Human Brain Mapping; received compensation for consulting services and/or speaking activities from Almiral, Alexion, Bayer, Biogen, Celgene, Eli Lilly, Genzyme, MerckSerono, Novartis, Roche, Sanofi, Takeda, and Teva Pharmaceutical Industries; and receives research support from Biogen Idec, Merck-Serono, Novartis, Roche, Teva Pharmaceutical Industries, Italian Ministry of 
Health, Fondazione Italiana Sclerosi Multipla, and ARiSLA (Fondazione Italiana di Ricerca per la SLA). F. Agosta is Section Editor of NeuroImage: Clinical; received compensation for consulting services and/or speaking activities from Philips, Novartis, Biogen Idec and Roche; and receives or has received research supports from the Italian Ministry of Health, AriSLA (Fondazione Italiana di Ricerca per la SLA), and the European Research Council.

\section{Acknowledgements}

We thank Professor Maria Luisa Gorno-Tempini, Memory and Aging Center, UCSF for providing us the Comprehensive Affect Testing System.

\section{References}

Abidi, M., Marco, G., Couillandre, A., Feron, M., Mseddi, E., Termoz, N., Querin, G., Pradat, P.-F., Bede, P., 2020. Adaptive functional reorganization in amyotrophic lateral sclerosis: coexisting degenerative and compensatory changes. Eur. J. Neurol. 27 (1), 121-128.

Aho-Ozhan, H.E., Keller, J., Heimrath, J., Uttner, I., Kassubek, J., Birbaumer, N. Ludolph, A.C., Lule, D., 2016. Perception of emotional facial expressions in amyotrophic lateral sclerosis (als) at behavioural and brain metabolic level. PLoS One 11 (10), e0164655.

Andrews, S.C., Staios, M., Howe, J., Reardon, K., Fisher, F., 2017. Multimodal emotion processing deficits are present in amyotrophic lateral sclerosis. Neuropsychology 31 (3), 304-310. https://doi.org/10.1037/neu0000323.

Arshad, F., Paplikar, A., Mekala, S., Varghese, F., Purushothaman, V., Kumar, D., Shingavi, L., Vengalil, S., Ramakrishnan, S., Yadav, R., Pal, P., Nalini, A., Alladi, S., 2020. Social cognition deficits are pervasive across both classical and overlap frontotemporal dementia syndromes. Dement Geriatr. Cogn. Disord. Extra 10 (3), 115-126. https://doi.org/10.1159/000511329.

Bede, P., Bokde, A., Elamin, M., Byrne, S., McLaughlin, R.L., Jordan, N., Hampel, H., Gallagher, L., Lynch, C., Fagan, A.J., Pender, N., Hardiman, O., 2013a. Grey matter correlates of clinical variables in amyotrophic lateral sclerosis (ALS): a neuroimaging study of ALS motor phenotype heterogeneity and cortical focality. J. Neurol. Neurosurg. Psychiatry 84 (7), 766-773.

Bede, P., Elamin, M., Byrne, S., McLaughlin, R.L., Kenna, K., Vajda, A., Pender, N., Bradley, D.G., Hardiman, O., 2013b. Basal ganglia involvement in amyotrophic lateral sclerosis. Neurology 81 (24), 2107-2115.

Beeldman, E., Raaphorst, J., Klein Twennaar, M., Govaarts, R., Pijnenburg, Y.A.L., de Haan, R.J., de Visser, M., Schmand, B.A., 2018. The cognitive profile of behavioural variant FTD and its similarities with ALS: a systematic review and meta-analysis. J. Neurol. Neurosurg. Psychiatry 89 (9), 995-1002.

Benbrika, S., Desgranges, B., Eustache, F., Viader, F., 2019. Cognitive, emotional and psychological manifestations in amyotrophic lateral sclerosis at baseline and overtime: a review. Front. Neurosci. 13, 951.

Bora, E., 2017. Meta-analysis of social cognition in amyotrophic lateral sclerosis. Cortex $88,1-7$.

Brettschneider, J., Del Tredici, K., Toledo, J.B., Robinson, J.L., Irwin, D.J., Grossman, M., Suh, EunRan, Van Deerlin, V.M., Wood, E.M., Baek, Y., Kwong, L., Lee, E.B., Elman, L., McCluskey, L., Fang, L., Feldengut, S., Ludolph, A.C., Lee, V.-Y., Braak, H., Trojanowski, J.Q., 2013. Stages of pTDP-43 pathology in amyotrophic lateral sclerosis: ALS Stages. Ann. Neurol. 74 (1), 20-38.

Brooks, B.R., Miller, R.G., Swash, M., Munsat, T.L., 2000. El Escorial revisited: revised criteria for the diagnosis of amyotrophic lateral sclerosis. Amyotroph. Lateral Scler. Other Motor Neuron Disord. 1 (5), 293-299.

Caga, J., Hsieh, S., Lillo, P., Dudley, K., Mioshi, E., 2019. The impact of cognitive and behavioral symptoms on als patients and their caregivers. Front. Neurol. 10, 192.

Calder, A.J., Beaver, J.D., Davis, M.H., van Ditzhuijzen, J., Keane, J., Lawrence, A.D., 2007. Disgust sensitivity predicts the insula and pallidal response to pictures of disgusting foods. Eur. J. Neurosci. 25 (11), 3422-3428.

Castelnovo, V., Canu, E., Calderaro, D., Riva, N., Poletti, B., Basaia, S., Solca, F., Silani, V., Filippi, M., Agosta, F., 2020. Progression of brain functional connectivity and frontal cognitive dysfunction in ALS. NeuroImage: Clin. 28, 102509. https://doi. org/10.1016/j.nicl.2020.102509.

Castelnovo, V., Canu, E., Riva, N., Poletti, B., Cividini, C., Fontana, A., Solca, F., Silani, V., Filippi, M., Agosta, F., 2021. Progression of cognitive and behavioral disturbances in motor neuron diseases assessed using standard and computer-based batteries. Amyotroph. Lateral Scler. Frontotemporal Degeneration 22 (3-4), 223-236.

Castillo-Huitron, N.M., Naranjo, E.J., Santos-Fita, D., Estrada-Lugo, E., 2020. The importance of human emotions for wildlife conservation. Front. Psychol. 11, 1277.

Cedarbaum, J.M., Stambler, N., Malta, E., Fuller, C., Hilt, D., Thurmond, B. Nakanishi, A., 1999. The ALSFRS-R: a revised ALS functional rating scale that incorporates assessments of respiratory function. J. Neurol. Sci. 169 (1-2), 13-21.

Cerami, C., Dodich, A., Canessa, N., Crespi, C., Iannaccone, S., Corbo, M., Lunetta, C., Consonni, M., Scola, E., Falini, A., Cappa, S.F., 2014. Emotional empathy in amyotrophic lateral sclerosis: a behavioural and voxel-based morphometry study. Amyotroph. Lateral Scler. Frontotemporal Degeneration 15 (1-2), 21-29.

Consonni, M., Catricalà, E., Dalla Bella, E., Gessa, V.C., Lauria, G., Cappa, S.F., 2016. Beyond the consensus criteria: multiple cognitive profiles in amyotrophic lateral sclerosis? Cortex 81, 162-167.
Crespi, C., Cerami, C., Dodich, A., Canessa, N., Arpone, M., Iannaccone, S., Corbo, M., Lunetta, C., Scola, E., Falini, A., Cappa, S.F., 2014. Microstructural white matter correlates of emotion recognition impairment in Amyotrophic Lateral Sclerosis. Cortex 53, 1-8.

Crespi, C., Cerami, C., Dodich, A., Canessa, N., Iannaccone, S., Corbo, M., Lunetta, C., Falini, A., Cappa, S.F., Zhou, J., 2016. Microstructural Correlates of Emotional Attribution Impairment in Non-Demented Patients with Amyotrophic Lateral Sclerosis. PLoS ONE 11 (8), e0161034. https://doi.org/10.1371/journal. pone.016103410.1371/journal.pone.0161034.g00110.1371/journal.pone.0161034. g00210.1371/journal.pone.0161034.g00310.1371/journal.pone.0161034. t00110.1371/journal.pone.0161034.t00210.1371/journal.pone.0161034. t00310.1371/journal.pone.0161034.s001.

Eckart, J.A., Sturm, V.E., Miller, B.L., Levenson, R.W., 2012. Diminished disgust reactivity in behavioral variant frontotemporal dementia. Neuropsychologia 50 (5), 786-790.

Feron, M., Couillandre, A., Mseddi, E., Termoz, N., Abidi, M., Bardinet, E., Delgadillo, D., Lenglet, T., Querin, G., Welter, M.-L., Le Forestier, N., Salachas, F., Bruneteau, G., del Mar Amador, M., Debs, R., Lacomblez, L., Meininger, V., Pélégrini-Issac, M., Bede, P., Pradat, P.-F., de Marco, G., 2018. Extrapyramidal deficits in ALS: a combined biomechanical and neuroimaging study. J. Neurol. 265 (9), 2125-2136.

Froming, K., Levy, M., Schaffer, S., Ekman, P., 2006. The comprehensive affect testing system. Psychology Software Inc.

Girardi, A., MacPherson, S.E., Abrahams, S., 2011. Deficits in emotional and social cognition in amyotrophic lateral sclerosis. Neuropsychology 25 (1), 53-65. https:// doi.org/10.1037/a0020357.

Guo, C.C., Sturm, V.E., Zhou, J., Gennatas, E.D., Trujillo, A.J., Hua, A.Y., Crawford, R., Stables, L., Kramer, J.H., Rankin, K., Levenson, R.W., Rosen, H.J., Miller, B.L., Seeley, W.W., 2016. Dominant hemisphere lateralization of cortical parasympathetic control as revealed by frontotemporal dementia. PNAS 113 (17), E2430-E2439.

Ho, C.-Y., Berridge, K.C., 2014. Excessive disgust caused by brain lesions or temporary inactivations: mapping hotspots of the nucleus accumbens and ventral pallidum. Eur. J. Neurosci. 40 (10), 3556-3572.

Holtmann, O., Bruchmann, M., Mönig, C., Schwindt, W., Melzer, N., Miltner, W.H.R., Straube, T., 2020. Lateralized deficits of disgust processing after insula-basal ganglia damage. Front. Psychol. 11 https://doi.org/10.3389/fpsyg.2020.0142910.3389/ fpsyg.2020.01429.s001.

Lule, D., Diekmann, V., Anders, S., Kassubek, J., Kubler, A., Ludolph, A.C., Birbaumer, N., 2007. Brain responses to emotional stimuli in patients with amyotrophic lateral sclerosis (als). J. Neurol. 254 (4), 519-527.

Lule, D., Kurt, A., Jurgens, R., Kassubek, J., Diekmann, V., Kraft, E., Neumann, N., Ludolph, A.C., Birbaumer, N., Anders, S., 2005. Emotional responding in amyotrophic lateral sclerosis. J. Neurol. 252 (12), 1517-1524.

Machts, J., Loewe, K., Kaufmann, J., Jakubiczka, S., Abdulla, S., Petri, S., Dengler, R., Heinze, H.-J., Vielhaber, S., Schoenfeld, M.A., Bede, P., 2015. Basal ganglia pathology in ALS is associated with neuropsychological deficits. Neurology 85 (15), 1301-1309.

Murphy, F.C., Nimmo-Smith, I., Lawrence, A.D., 2003. Functional neuroanatomy of emotions: A meta-analysis. Cogn. Affect. Behav. Neurosci. 3 (3), 207-233.

Oh, S.-i., Oh, K.-W., Kim, H.-J., Park, J.-S., Kim, S.H., 2016. Impaired perception of emotional expression in amyotrophic lateral sclerosis. J. Clin. Neurol. 12 (3), 295. https://doi.org/10.3988/jcn.2016.12.3.295.

Palmieri, A., Naccarato, M., Abrahams, S., Bonato, M., D’Ascenzo, C., Balestreri, S., Cima, V., Querin, G., Dal Borgo, R., Barachino, L., Volpato, C., Semenza, C., Pegoraro, E., Angelini, C., Sorarù, G., 2010. Right hemisphere dysfunction and emotional processing in ALS: an fMRI study. J. Neurol. 257 (12), 1970-1978.

Papagno, C., Pisoni, A., Mattavelli, G., Casarotti, A., Comi, A., Fumagalli, F., Vernice, M., Fava, E., Riva, M., Bello, L., 2016. Specific disgust processing in the left insula: New evidence from direct electrical stimulation. Neuropsychologia 84, 29-35.

Papps, B., Abrahams, S., Wicks, P., Leigh, P.N., Goldstein, L.H., 2005. Changes in memory for emotional material in amyotrophic lateral sclerosis (ALS). Neuropsychologia 43 (8), 1107-1114.

Pozzi, L., Valenza, F., Mosca, L., Dal Mas, A., Domi, T., Romano, A., Tarlarini, C., Falzone, Y.M., Tremolizzo, L., Sorarù, G., Cerri, F., Ferraro, P.M., Basaia, S., Agosta, F., Fazio, R., Comola, M., Comi, G., Ferrari, M., Quattrini, A., Lunetta, C., Penco, S., Bonanomi, D., Carrera, P., Riva, N., 2017. TBK1 mutations in Italian patients with amyotrophic lateral sclerosis: genetic and functional characterisation. J. Neurol. Neurosurg. Psychiatry 88 (10), 869-875.

Renton, A., Majounie, E., Waite, A., Simón-Sánchez, J., Rollinson, S., Gibbs, J.R., Schymick, J., Laaksovirta, H., van Swieten, J., Myllykangas, L., Kalimo, H., Paetau, A., Abramzon, Y., Remes, A., Kaganovich, A., Scholz, S., Duckworth, J., Ding, J., Harmer, D., Hernandez, D., Johnson, J., Mok, K., Ryten, M., Trabzuni, D., Guerreiro, R., Orrell, R., Neal, J., Murray, A., Pearson, J., Jansen, I., Sondervan, D., Seelaar, H., Blake, D., Young, K., Halliwell, N., Callister, J., Toulson, G., Richardson, A., Gerhard, A., Snowden, J., Mann, D., Neary, D., Nalls, M., Peuralinna, T., Jansson, L., Isoviita, V.-M., Kaivorinne, A.-L., Hölttä-Vuori, M., Ikonen, E., Sulkava, R., Benatar, M., Wuu, J., Chiò, A., Restagno, G., Borghero, G., Sabatelli, M., Heckerman, D., Rogaeva, E., Zinman, L., Rothstein, J., Sendtner, M., Drepper, C., Eichler, E., Alkan, C., Abdullaev, Z., Pack, S., Dutra, A., Pak, E., Hardy, J., Singleton, A., Williams, N., Heutink, P., Pickering-Brown, S., Morris, H., Tienari, P., Traynor, B., 2011. A Hexanucleotide Repeat Expansion in C9ORF72 Is the Cause of Chromosome 9p21-Linked ALS-FTD. Neuron 72 (2), 257-268.

Royet, J.-P., Plailly, J., Delon-Martin, C., Kareken, D.A., Segebarth, C., 2003. fMRI of emotional responses to odors: NeuroImage 20 (2), 713-728.

Rozin, P., Haidt, J., Fincher, K., 2009. Psychology. From oral to moral. Science 323 (5918), 1179-1180. 
Savage, S.A., Lillo, P., Kumfor, F., Kiernan, M.C., Piguet, O., Hodges, J.R., 2014. Emotion processing deficits distinguish pure amyotrophic lateral sclerosis from frontotemporal dementia. Amyotroph. Lateral Scler. Frontotemporal Degeneration 15 (1-2), 39-46.

Small, D.M., Gregory, M.D., Mak, Y.E., Gitelman, D., Mesulam, M.M., Parrish, T., 2003. Dissociation of neural representation of intensity and affective valuation in human gustation. Neuron 39 (4), 701-711.

Sprengelmeyer, R., Rausch, M., Eysel, U.T., Przuntek, H., 1998. Neural structures associated with recognition of facial expressions of basic emotions. Proc. Biol. Sci. 265 (1409), 1927-1931.

Strong, M.J., Abrahams, S., Goldstein, L.H., Woolley, S., Mclaughlin, P., Snowden, J., Mioshi, E., Roberts-South, A., Benatar, M., HortobáGyi, T., Rosenfeld, J., Silani, V., Ince, P.G., Turner, M.R., 2017. Amyotrophic lateral sclerosis - frontotemporal spectrum disorder (ALS-FTSD): revised diagnostic criteria. Amyotroph. Lateral Scler. Frontotemporal Degeneration 18 (3-4), 153-174.

Swinnen, B., Robberecht, W., 2014. The phenotypic variability of amyotrophic lateral sclerosis. Nat. Rev. Neurol. 10 (11), 661-670.

Tae, W.-S., Sung, J.H., Baek, S.-H., Lee, C.-N., Kim, B.-J., 2020. Shape analysis of the subcortical nuclei in amyotrophic lateral sclerosis without cognitive impairment. J. Clin. Neurol. 16 (4), 592. https://doi.org/10.3988/jcn.2020.16.4.592.
Verstraete, E., Veldink, J.H., van den Berg, L.H., van den Heuvel, M.P., 2014. Structural brain network imaging shows expanding disconnection of the motor system in amyotrophic lateral sclerosis: Expanding Motor Disconnection in ALS. Hum. Brain Mapp. 35 (4), 1351-1361.

Watermeyer, T.J., Brown, R.G., Sidle, K.C., Oliver, D.J., Allen, C., Karlsson, J., Ellis, C.M., Shaw, C.E., Al-Chalabi, A., Goldstein, L.H., 2015. Executive dysfunction predicts social cognition impairment in amyotrophic lateral sclerosis. J. Neurol. 262 (7), 1681-1690.

Werner, K.H., Roberts, N.A., Rosen, H.J., Dean, D.L., Kramer, J.H., Weiner, M.W. Miller, B.L., Levenson, R.W., 2007. Emotional reactivity and emotion recognition in frontotemporal lobar degeneration. Neurology 69 (2), 148-155.

Westeneng, H.-J., Verstraete, E., Walhout, R., Schmidt, R., Hendrikse, J., Veldink, J.H., van den Heuvel, M.P., van den Berg, L.H., 2015. Subcortical structures in amyotrophic lateral sclerosis. Neurobiol. Aging 36 (2), 1075-1082.

Wicker, B., Keysers, C., Plailly, J., Royet, J.-P., Gallese, V., Rizzolatti, G., 2003. Both of us disgusted in my insula. Neuron 40 (3), 655-664.

Zimmerman, E.K., Eslinger, P.J., Simmons, Z., Barrett, A.M., 2007. Emotional perception deficits in amyotrophic lateral sclerosis. Cogn. Behav. Neurol. 20 (2), 79-82. 